\title{
Use of Health Apps and Wearable Devices: Survey Among Italian Associations for Patient Advocacy
}

Paola Mosconi $^{1^{*}}$, Biol Sci D; Silvia Radrezza ${ }^{1 *}$, Pharm D; Emanuele Lettieri ${ }^{2}$, PhD Management Engineering; Eugenio Santoro $^{3 *}$, Comp Sci D

${ }^{1}$ Laboratory for Medical Research and Consumer Involvement, Department of Public Health, Istituto di Ricerche Farmacologiche Mario Negri IRCCS, Milan, Italy

${ }^{2}$ Department of Management, Economics and Industrial Engineering, Politecnico of Milan, Milan, Italy

${ }^{3}$ Laboratory of Medical Informatics, Department of Public Health, Istituto di Ricerche Farmacologiche Mario Negri IRCCS, Milan, Italy

*these authors contributed equally

\section{Corresponding Author:}

Eugenio Santoro, Comp Sci D

Laboratory of Medical Informatics

Department of Public Health

Istituto di Ricerche Farmacologiche Mario Negri IRCCS

19, Via Giuseppe la Masa

Milan, 20156

Italy

Phone: 390239014 ext 562

Fax: 390233200231

Email: eugenio.santoro@marionegri.it

\section{Abstract}

Background: Technological tools such as Web-based social networks, telemedicine, apps, or wearable devices are becoming more widespread in health care like elsewhere. Although patients are the main users, for example, to monitor symptoms and clinical parameters or to communicate with the doctor, their perspective is seldom analyzed, and to the best of our knowledge, no one has focused on the patients' health care advocacy associations' point of view.

Objective: The objective of this study was to assess patients' health care advocacy associations' opinions about the use, usefulness, obstacles, negative aspects, and impact of health apps and wearable devices through a Web-based survey.

Methods: We conducted a Web-based survey through SurveyMonkey over nearly 3 months. Participants were contacted via an email explaining the aims of the survey and providing a link to complete the Web-based questionnaire. All the 20 items were mandatory, and the anonymized data were collected automatically into a database. Only fully completed questionnaires were considered for analysis.

Results: We contacted 1998 patients' health care advocacy associations; a total of 258 questionnaires were received back (response rate $12.91 \%$ ), and 227 of the received questionnaires were fully completed (completion rate 88.0\%). Informative apps, hospital apps for viewing medical reports or booking visits, and those for monitoring physical activity are the most used. They are considered especially useful to improve patients' engagement and compliance with treatment. Wearable devices to check physical activity and glycemia are the most widespread considering, again, their benefits in increasing patients' involvement and treatment compliance. For health apps and wearable devices, the main obstacles to their use are personal and technical reasons; the risk of overmedicalization is considered the most negative aspect of their constant use, while privacy and confidentiality of data are not rated a limitation. No statistical difference was found on stratifying the answers by responders' technological level $(P=.30)$, age $(P=.10)$, and the composition of the association's advisory board $(P=.15)$.

Conclusions: According to responders, health apps and wearable devices are sufficiently known and used and are considered potential supports for greater involvement in health management. However, there are still obstacles to their adoption, and the developers need to work to make them more accessible and more useful. The involvement of patients and their associations in planning services and products based on these technologies (as well as others) would be desirable to overcome these barriers and boost awareness about privacy and the confidentiality of data. 
(JMIR Mhealth Uhealth 2019;7(1):e10242) doi: 10.2196/10242

\section{KEYWORDS}

health apps; mobile phone; Web-based survey; patients' health care advocacy associations; wearable devices

\section{Introduction}

New technologies, connectivity, and availability of the internet have boosted the development of mobile apps and wearable devices in the last decade. Those for health and care focus mainly on the management of chronic conditions such as diabetes [1], cardiovascular diseases [2], and specific populations or conditions [3,4]. Moreover, these devices have gained ground in health self-monitoring and preventive medicine [5]. Italy is the second most frequent worldwide user of new technology, particularly wearables, after the United States and before Germany and France [6].

Electronic health (eHealth) and medical devices such as apps and wearable devices are becoming more and more important in health debate. In the past year alone, health apps have grown by nearly 78,000 units, reaching a total of 325,000 registered [7]. Despite their spread, however, the use of these new technologies arouses discussions about the collection and sharing of data, focused on their protection, privacy, accuracy, and reliability $[8,9]$.

A recent study about the most downloaded "mobile health (mHealth) apps" found that only $30.5 \%$ had a privacy policy. However, many of these documents used technical language not accessible to most lay people or they did not focus enough on the app itself $[10,11]$. Moreover, health data are often stored in the "cloud" so we cannot know where it is exactly, making it not completely safe [12].

There is still debate in the literature on the use and efficacy of apps and wearable devices to help patients collect and access their clinical data [13]. To date, patients' engagement is considered an important clinical outcome, and these tools could make them more responsible for treatment management, monitoring symptoms, identifying risk factors, and how best to prevent other diseases, for example, by changing their lifestyle [14]. Health apps or wearable devices could be suitable above all for chronic diseases. Evidence of this comes from a systematic review based on randomized controlled trials, where Yuan et al reported that the use of mobile apps by diabetic adults lowered glycemia more than standard care alone [15].

Several surveys on consumer perspective [16,17], use of mHealth app [18], and wearable devices [19] have been conducted regarding the use of technological tools in health care; however, to the best of our knowledge, none has been related to patients' health care advocacy associations. These associations, in Italy, like in other industrialized countries, are a growing reference point in the public health debate and innovation, influencing research and the political agenda [20]. The associations are spokespersons for a multiplicity of opinions and collecting their points of view is the best way to actually engage consumers and patients better. We conducted an observational study through a Web-based survey to analyze the representatives of health care advocacy associations' point of view.

\section{Methods}

\section{Methodology}

The Web-based survey was close, voluntary, and took only a few minutes to complete. No incentive was given. The SurveyMonkey Web-based survey service [21] was used to design the questionnaire, manage the survey, and collect data. The Web questionnaire was 5 pages long, and all data were anonymized and protected by Norton and TRUSTe.

An email was sent to 1998 contacts, describing the survey and including a link inviting them to complete the questionnaire. Reminder emails were sent after 3, 5, and 7 weeks. The questionnaire was organized in a series of linked pages (multiple-item screens) with electronic instructions to facilitate the flow. A progress indicator was permanently visible, and compilers could enter a personal comment for each question. The questions were in bold type, and the answers had optional buttons.

According to the "Checklist for Reporting Results of Internet E-Surveys" (CHERRIES), all the questions, except the last one, were mandatory to obtain more solid data on the endpoints of the survey. To guarantee the possibility of answering, most questions provided a nonresponse option, that is, "I don't know." Again, based on the CHERRIES checklist, we analyzed only completed questionnaires, excluding questionnaires that had missing data due to the responder stopping early and leaving the website.

If all answers were not completed, it was not possible to continue and confirm the questionnaire. A "back button" was provided to change answers before submitting them, but thereafter, no further changes were allowed. The answers were collected automatically in the SurveyMonkey database. Overall, 6 questionnaires were filled manually in the database by the coordinator center to clean up any technical problems of the responders. Of note, under Italian law, ethical approval was not required for this kind of survey.

\section{Development of the Questionnaire}

We conducted a literature review in PubMed using the following keywords: "digital technologies," "survey," "questionnaire," "eHealth," "mHealth," "digital health," "digital innovation," and "development." We retrieved a number of surveys about "digital innovation" involving citizens but none involved patients' health care advocacy associations. Based on the material collected, we drafted 20 items about the use, usefulness, obstacles, negative aspects, and impact related to eHealth technologies, focusing on health apps and wearable devices.

In addition, we recorded the characteristics of the patients' health care advocacy associations contacted (year of foundation, 
setting, geographic distribution, and current composition of the advisory board) and of responders (sex, age, education, personal use of health apps, or wearable devices) to have a complete framework of the sample (see Multimedia Appendix 1). In this regard, some previous studies showed that age and individual technological level influenced a person's interest in the adoption of health apps also in clinical situations [22].

We pretested the questionnaire with the collaboration of 16 representatives of patients' health care advocacy associations to assess its readability, clarity, and completeness and to collect suggestions. Seven representatives answered, and a general positive consensus was gathered; hence, no major changes were required.

\section{Recruitment}

We started from a database of patients' health care advocacy associations available at the "Laboratory for Medical Research and Consumer Involvement" $(\mathrm{n}=2087)$; duplicate and wrong email addresses were removed $(\mathrm{n}=98)$. This database, developed in 2004, includes contacts of members of the board of associations-no single member-who had participated in previous research projects, training courses, and initiatives.

We sent one email invitation to each association, usually to the president of the association or a member of the board. The questionnaire asked for his or her personal opinion (see questions 7-10 and 14 in the Multimedia Appendix 1) and to report the common belief of the members represented (see questions 11-13 in the Multimedia Appendix 1).

The survey was announced through Web on the Mario Negri Institute websites and 2 patients' health care association websites; 9 health care associations requested to participate by contacting the coordinator center directly. Overall, 1998 patients' health care advocacy associations were reached via emails. A unique site visitor was permitted by checking the internet protocol address of responder. Results were presented according to CHERRIES" [23] and a similar guideline formulated by Bennett et al [24].

\section{Statistical Analysis}

Descriptive analyses were conducted using SAS version 9.4 (SAS Institute Inc) to cross variables according to several criteria. On the basis of the previous studies suggestions, we analyzed the pattern of answers by responders' age and their technological level. In addition, we considered the composition of the advisory board of the patients' health care advocacy associations as a possible confounding factor. A statistical test $(P$ value) was expected only for results that gave significant patterns using a predetermined alpha level of .05.

\section{Results}

The survey was open from March 23 to June 8, 2017. A total of 258 answers were collected, giving a response rate of $12.91 \%$
(258/1998). We analyzed 227 completed questionnaires, as 31 responders dropped out before completing the questionnaire, giving a completion rate of $88.0 \%(227 / 258)$.

Tables 1 and 2 summarize the main characteristics of the patients' health care advocacy associations and responders, respectively. Out of 227 responders, 121 (53.3\%) worked locally, while $43(18.9 \%)$ and $63(27.8 \%)$ worked on the regional and national levels, respectively. Most associations were based in the north of Italy. The advisory board comprised all or most of the patients or relatives for $58.6 \%$ (133/227) answers; furthermore, $18.1 \%(41 / 227)$ responders stated that there were no patients or relatives on their board. Respondents were aged 25-88 (mean age 56, SD 12) years; females and males were fairly represented, and $46.3 \%$ (105/227) respondents reported an appreciable level of technology, using at least one health app or wearable device, or both.

According to the 227 participants, Web-based social networks were used for health communication, promotion, or grouping patients with a specific disease, and telemedicine had a great impact on health care out of all technological innovations, with $183(80.6 \%)$ responders and $178(78.4 \%)$ of preferences, respectively; these were followed by wearable devices, such as smart-watches or wristbands, and health apps, with 148 (65.2\%) and $146(64.3 \%)$ responders, respectively. However, they foresaw that in the next 3 years, the impact would increase more for health apps, wearable devices, and telemedicine services than for Web-based social networks (Table 3).

Among health apps, those providing health and disease information, hospital apps for services such as viewing medical reports or booking visits, and those for tracking fitness or physical activity were the most used by members of health care advocacy associations, with 149 (65.6\%), 118 (52.0\%), and 116 (51.1\%) of 227 participants, respectively. Apps to improve treatment and medication compliance, health or condition trackers, and diet or nutrition apps followed with $106(46.7 \%)$, $96(42.2 \%)$, and $80(35.2 \%)$ of 227 responders, respectively. Symptom-checker apps for self-diagnosis were the least used, with $22.0 \%(50 / 227)$ positive answers. Wearable devices monitoring physical activity and glycemia were the most widespread among 227 respondents-110 (48.5\%) and 108 (47.6\%), respectively-followed by those monitoring heart rate and blood pressure, weight, and sleep tracking, with 106 (46.7\%), 88 (38.8\%), and $64(28.2 \%)$ respondents, respectively.

From the point of view of patients' health care advocacy associations' representatives, health apps and wearable devices are not only useful to improve patients' engagement in their own health and treatment compliance but also to help them understand their health status and conditions, enhancing the communication between patients and physicians, and reducing health care costs (Table 4). 
Table 1. Characteristics of patients' health care advocacy associations $(\mathrm{N}=227)$.

\begin{tabular}{|c|c|}
\hline Characteristics & Associations, n (\%) \\
\hline \multicolumn{2}{|l|}{ Year of foundation } \\
\hline 1940-1999 & $119(52.4)$ \\
\hline $2000-2016$ & $108(47.6)$ \\
\hline \multicolumn{2}{|l|}{ Types } \\
\hline Oncology & $38(16.7)$ \\
\hline Diabetes & $34(15.0)$ \\
\hline Rare diseases & $28(12.3)$ \\
\hline Neurology & $19(8.4)$ \\
\hline Cardiovascular & $15(6.6)$ \\
\hline Disability & $12(5.3)$ \\
\hline Breast cancer & $13(5.7)$ \\
\hline Pediatric & $7(3.1)$ \\
\hline AIDS & $5(2.2)$ \\
\hline Brain-injured & $4(1.8)$ \\
\hline Autism & $2(0.9)$ \\
\hline Asthma & $1(0.4)$ \\
\hline Other & 49 (21.6) \\
\hline \multicolumn{2}{|l|}{ Geographic distribution } \\
\hline North & $126(55.5)$ \\
\hline Center & $50(22.0)$ \\
\hline South-Islands & $51(22.5)$ \\
\hline \multicolumn{2}{|l|}{ Weblink } \\
\hline Website & $203(89.4)$ \\
\hline Facebook account & $186(81.9)$ \\
\hline Twitter account & $80(35.2)$ \\
\hline YouTube channel & $74(32.6)$ \\
\hline Blog & $43(18.9)$ \\
\hline \multicolumn{2}{|l|}{ Advisory board } \\
\hline All members are patients or their relatives & $78(34.4)$ \\
\hline Most members are patients & $55(24.2)$ \\
\hline Patients' representatives are nearly half & $27(11.9)$ \\
\hline Patients' representatives are a minority & $26(11.5)$ \\
\hline There are no patients' representatives & $41(18.1)$ \\
\hline
\end{tabular}


Table 2. Characteristics of responders $(\mathrm{N}=227)$.

\begin{tabular}{|c|c|}
\hline Characteristics & Responders, n (\%) \\
\hline \multicolumn{2}{|l|}{ Sex } \\
\hline Males & $100(44.1)$ \\
\hline Females & $127(56.0)$ \\
\hline \multicolumn{2}{|l|}{ Age in years } \\
\hline$\leq 50$ & $67(29.5)$ \\
\hline $51-65$ & $106(46.7)$ \\
\hline$>65$ & $54(23.8)$ \\
\hline \multicolumn{2}{|l|}{ Education level } \\
\hline Elementary school & $1(0.4)$ \\
\hline Secondary school & $10(4.4)$ \\
\hline High school & $93(41.0)$ \\
\hline Degree or superior & $121(53.3)$ \\
\hline Other & $2(0.9)$ \\
\hline \multicolumn{2}{|c|}{ Personal use of health app or wearable } \\
\hline Both & $38(16.7)$ \\
\hline Only health app & $50(22.0)$ \\
\hline Only wearable & $17(7.5)$ \\
\hline None & $122(53.7)$ \\
\hline
\end{tabular}

Table 3. Impact of technological tools on medical care and health $(\mathrm{N}=227)$.

\begin{tabular}{|c|c|c|c|c|}
\hline \multirow[t]{3}{*}{ Technological tool } & \multicolumn{4}{|c|}{ Responders, n (\%) } \\
\hline & \multicolumn{2}{|c|}{ Current impact } & \multicolumn{2}{|c|}{ Future impact } \\
\hline & Yes & No & Yes & No \\
\hline Health app & $146(64.3)$ & $81(35.7)$ & $192(84.6)$ & $35(15.4)$ \\
\hline Wearable & $148(65.2)$ & $79(34.8)$ & 183 (80.6) & $44(19.4)$ \\
\hline Telemedicine & 178 (78.4) & 49 (21.6) & $211(93.0)$ & $16(7.1)$ \\
\hline Social network & $183(80.6)$ & 44 (19.4) & $197(86.8)$ & $30(13.2)$ \\
\hline
\end{tabular}

Table 4. Utility of health apps and wearables in health care $(\mathrm{N}=227)$.

\begin{tabular}{lll}
\hline Utility & \multicolumn{2}{l}{ Responders, $\mathrm{n}(\%)$} \\
& Positive effect & Negative or no effect \\
\hline Empowerment in own health & $204(89.9)$ & $23(10.1)$ \\
Improve doctor-patient communication & $167(73.6)$ & $60(26.4)$ \\
Understand own health condition & $179(78.9)$ & $48(21.1)$ \\
Reduce public health costs & $127(55.9)$ & $100(44.1)$ \\
Improve compliance & $186(81.9)$ & $41(18.1)$ \\
\hline
\end{tabular}

Responders reported that the main obstacles to the adoption of health apps and wearable devices among members of their health care advocacy associations were personal motivations, such as concern about not being able to use them, or technical reasons, including owning an unsuitable smartphone, followed by the lack of evidence of their usefulness, accuracy, and reliability.
Conversely, the lack of confidence in data protection and confidentiality seemed to restrict their use for only $31.3 \%$ $(71 / 227)$ responders. It was interesting to highlight that about a quarter of responders had no clear opinion about the privacy and accuracy of data collected through apps and wearable devices (Table 5). 
Table 5. Obstacles related to the use of health apps and wearables $(\mathrm{N}=227)$.

\begin{tabular}{llll}
\hline Obstacles & Yes, $\mathrm{n}(\%)$ & No, n (\%) & I don't know, n (\%) \\
\hline Technical barrier & $144(63.4)$ & $52(22.9)$ & $31(13.7)$ \\
Personal opinion & $144(63.4)$ & $48(21.2)$ & $35(15.4)$ \\
Low trust in recorded data utility & $73(32.2)$ & $89(39.2)$ & $65(28.6)$ \\
Low trust in data reservation and privacy & $70(30.8)$ & $100(44.1)$ & $57(25.1)$ \\
Low trust in recorded data reliability and quality & $71(31.3)$ & $80(35.2)$ & $76(33.5)$ \\
Low example of their utility in public health & $90(39.6)$ & $59(26.0)$ & $78(34.4)$ \\
\hline
\end{tabular}

Table 6. Negative aspects of constant adoption of health apps and wearable devices $(\mathrm{N}=227)$.

\begin{tabular}{lll}
\hline Negative aspects & Yes, $\mathrm{n}(\%)$ & No, $\mathrm{n}(\%)$ \\
\hline Become dependent & $148(65.2)$ & $79(34.8)$ \\
No privacy & $70(30.8)$ & $157(69.2)$ \\
Excessive control of own health & $149(65.6)$ & $78(34.4)$ \\
Overmedicalization & $160(70.5)$ & $67(29.5)$ \\
Weaken doctor-patient communication & $101(44.5)$ & $126(55.5)$
\end{tabular}

Among negative aspects or risks about the use of health apps and wearable devices, respondents considered first overmedicalization (ie, the overuse of drugs, supplements, and medical devices or scheduling medical examinations even if they are not really needed), followed by the risk of becoming dependent on technology, or weakening patient-doctor communication (Table 6). The lack of confidence in the protection and confidentiality of data was considered a negative aspect only by $30.8 \%(70 / 227)$ responders in agreement with the answers related to the obstacles reported in Table 5.

When we asked about the kind of health apps on which developers should focus in future to improve medical care and health, respondents put first those improving and disseminating health services and tools, with out of $227,186(81.9 \%)$ preferences, followed by those boosting compliance (175, $77.1 \%)$ and those monitoring vital signs $(156,68.7 \%)$, diet and nutrition $(147,64.8 \%)$, and physical activity $(137,60.4 \%)$. Of the 227 respondents, about two-third $(154,67.8 \%)$ asked to focus the efforts on informative health apps, while only 101 $(44.5 \%)$ wanted more attention to symptom-checker apps. For wearable devices, the respondents stated that more attention could be paid to heart rate and blood pressure monitoring (167, $73.4 \%)$, glycemia $(165,72.7 \%)$, weight monitoring (139, $61.2 \%)$, and fitness trackers $(136 / 227,60.0 \%)$; less interest was shown in sleep trackers $(112,49.3 \%)$.

Data about the use, usefulness for health care, obstacles, and negative aspects of health apps and wearable devices were stratified by the respondents' age ( $\geq 58$ years), technological level (users of one health app or one wearable device at least compared to not users), and the composition of the association's advisory board (all or most are patients compared to few or no patients). There were no statistically significant associations, although there was a slight influence of the technological level of responders. High technological level responders reported a greater positive impact of all technological tools (health apps, wearable devices, telemedicine, and Web-based social networks) on health and health care, now and in the future than the lower technological level responders. In addition, attitudes were different toward the usefulness of health apps and wearable devices. According to high technological responders, patients' engagement and compliance with treatment related to these tools were most important. In addition, higher technological level responders considered the risk of becoming dependent and excessive control of one's own health less important than the less technological ones.

\section{Discussion}

This study offers an exclusive view of patients' health care advocacy associations' opinions about eHealth technological tools that have not yet been well explored. The results suggest that the most commonly used health apps appear to be informative apps, apps providing access to hospital services, and fitness or physical activity tracking apps, while the favorite wearable devices are those for fitness, blood glucose, and heart rate monitoring. Our findings are different from those reported in a recent study based on citizens where fitness, diet or nutrition, and symptom navigator apps were at the top of the rankings with $59 \%, 52 \%$, and $36 \%$ of use, respectively [17]. In addition, our results differ from those reported in a recent study focused on consumer's perceived attitudes about wearable devices in health monitoring, in which exercise coaching (61\%) and location tracking (59\%) came first [19].

Despite this, our results are similar to those from a study conducted on patients and confirm how both health apps and wearable devices can be used for patient engagement. In fact, a recent survey found that the main reasons for their adoption were chronic disease management $(81 \%)$, support for medical adherence (66\%), and fitness tracking (46\%) [13].

Respondents are optimistic about the future of health apps and wearable devices. They suggest that in the near future, developers should focus on apps providing more services, 
increasing drug and therapy compliance, and monitoring vital signs.

The gaps between current opinion and needs may be explained considering that today's responders are concerned about the reliability of the data collected by health apps and wearable devices but are confident that in the future, more evidence will be provided to support their use and efficacy in collecting data for diseases monitoring and management. On the other hand, our survey shows that the lack of evidence of reliability and accuracy of health apps and wearable devices, along with difficulty in adopting them, are the main obstacles to their use.

About the accuracy - but also the effectiveness-of these tools, researchers need to raise the overall quality of interventional trials conducted on patients, focusing on mobile apps and wearable devices. These trials are still limited due to the short follow-up, low recruitment rate, and high proportion of withdrawals before the scheduled time. It is, therefore, hard to see whether they might become valuable for helping patients with their own health [25].

Other studies raised the question of discontinuing the use of health apps and wearable devices when the real setting is not taken into consideration. For example, a recent study showed that the majority of users increased their physical activity after purchasing a wearable device, but nearly one-third stopped tracking after just 6 months [26]. Another study found that 55\% of the 325,000 health apps available in the app stores are downloaded $<5000$ times and only $2 \%$ of all health apps count $>500,000$ monthly active users [7]. Fuller involvement of patients and their associations to identify specific needs could probably narrow this gap and make wearable devices and health apps more appealing and useful for engagement [27].

The lack of confidence in data protection and confidentiality seemed not to limit the use of health apps and wearable devices and did not appear to be one of the main negative aspects. This is very important because the adoption of apps and wearable devices in health care might give rise to challenges about security, data protection, and data reuse [8,9]. For example, a study on 79 apps certified as clinically safe and trustworthy by the "UK-National Health Service Health Apps Library" revealed that $89 \%$ of them transmitted information to Web-based services, and none encrypted personal information stored locally. Two-thirds of the apps sent personal information over the internet without encryption and $20 \%$ did not have a specific privacy policy [28]. However, it is interesting that about a quarter of our responders knew little about the question of data privacy and confidentiality; a possible explanation is that patients' representatives themselves do not know enough, necessitating more awareness and information. An alternative reason is that participants do not care much about these topics and are willing to exchange part of their data for a potential health care gain.

This survey has several limitations. First, respondents are representatives of health care advocacy associations and answered reporting their point of view and the patients' perspective. Second, as Italy has no central database of consumers' and patients' associations, we contacted a limited number of associations; hence, this sample may not be representative of all Italian situations and attitudes. The response rate, $12.91 \%$ (258/1998), may have increased the selection bias, but it agrees with other similar studies. The response rate of Web-based surveys is often low, and many strategies have been investigated to increase it [29]. Finally, the heterogeneity of the health care advocacy associations that participated could have added further selection bias.

In conclusion, the survey shows that health apps and wearable devices are sufficiently used and appreciated by patients as potential supports for greater engagement in their health. There are still obstacles to their use, however, on which developers should work to make them more accessible and more useful. The involvement of patients and their health care advocacy associations in designing services and products based on these technologies - and others - is desirable to overcome barriers and make their development and acceptance easier and more competitive.

\section{Acknowledgments}

Associations participating in the pretested questionnaire are as follows:

AMA Associazione malattia di Alzheimer, Associazione Centro Donna, Associazione Progetto Luna, ATRACTO Onlus, AVULSS di Palermo, Tarlov Italia Onlus, and Voglia di Vivere onlus.

Associations that have provided consent to be cited are as follows:

Familiari Cardiopatici Onlus, Un cuore per amico, ADA Associazione Diabetici Alcamese, ADOCM Crisalide, AFADOC Onlus, AGAD associazione Giovani e Adulti con Diabete Onlus, Mantova, AGD Catanzaro Associazione Giovani Diabetici, AGOP Onlus Associazione Genitori Oncologia Pediatrica, AIDO Associazione Italiana Donatori Organi tessuti e cellule, AITA Abruzzo Onlus, ALICe Sardegna, ANIAD Onlus Associazione Nazionale Italiana Atleti Diabetici, ANIO Onlus Associazione Nazionale per le Infezioni Osteoarticolari, ACLTI Associazione contro le Leucemie e i Tumori nell'Infanzia, AEL Onlus Associazione Emofilici Lazio, AGD Piemonte e Valle d'Aosta, AILS, AIMA Associazione Italiana Malattia di Alzheimer, AIRP Associazione Italiana Rene Policistico, AISA Sezione Lombarda Onlus, AISM, AISTOM Associazione Italiana Stomizzati, AITSaM Onlus Associazione Italiana Tutela Salute Mentale, ALA Milano Onlus, Albinit, ALOMAR Associazione Lombarda Malati Reumatici, Alteg, Alzheimer Uniti Roma Onlus, Amici del Cuore “A Borin" Padova, Amici del Cuore di Camposampiero e della Strada del Santo, Amici del Cuore Verbania, Amici di Gianni Brundu, AMOC Onlus Associazione Malati Oncologici Colonretto, ANED Associazione Nazionale Emodializzati Dialisi e Trapianto Onlus, ANGEA Associazione Nazionale Genitori Eczema Atopico E Allergie Alimentari Onlus, ANGSA La Spezia, ANLAIDS Onlus, ANVOLT Associazione Nazionale Volontari per la Lotta 
contro i Tumori Udine, APMAR Onlus Associazione Persone Con Malattie Reumatologiche e Rare, ASLIDIA Associazione Ligure per la lotta contro il Diabete Sanremo, ASNET Associazione Sarda Emodializzati e Trapiantati della Sardegna, ASRI Associazione Solidarietà Rifugiati e Immigrati, Associazione Sedna dei Diabetici Onlus, Associazione Traumi Cranici provincia di Reggio Emilia e Modena, Associazione Acromati Italiani, Associazione Aldo Perini Onlus, Associazione Amici Del Ceppo, Associazione Anastasis Onlus, Associazione Comunità Progetto Sud Onlus, Associazione culturale La Città di Pulcinella, Associazione di promozione sociale I Girasoli, Associazione Diabete Iglesias Carbonia ADIC Onlus, Associazione Diabete Versilia, Associazione Diabetici Area Pratese Onlus, Associazione Diabetici Basso Molise, Associazione Diabetici Copparo ADICO, Associazione Diabetici della provincia di Grosseto, Associazione Diabetici di Cinisello e comuni Limitrofi ADCL, Associazione Diabetici Marsicana, Associazione Genitori La Nostra Famiglia, Associazione Gianmarco De Maria, Associazione Giuliana Cerretti per l'Oncologia Onlus, Associazione Interzona, Associazione Iosempredonna Onlus, Associazione Italiana Celiachia Lombardia Onlus, Associazione Italiana Cistite Interstiziale, Associazione Italiana Dislipidemie Ereditarie, Associazione Italiana Estrofia Vescicale Epispadia Onlus, Associazione Italiana Laringectomizzati AILAR Onlus, Associazione Italiana Pazienti Anticoagulati, Firenze, Associazione Italiana Pazienti BPCO, Associazione Italiana Persone Down, Belluno, Associazione Italiana Stomizzati Sicilia, Associazione Ligure Sindrome x-fragile onlus, Associazione Nazionale Alfa1 AT, Associazione Nazionale Porpora Trombotica Trombocitopenica Onlus, Associazione Onlus Carmine Speranza, Associazione Parkinson Rovigo \& Amici Onlus, Associazione Progetto Endometriosi, Associazione Reggiana per la Lotta e Cura dell'AIDS Onlus, Associazione Sarda Paratetraplegici, Associazione Scientifica Culturale Alter Ego, Associazione Serena a Palermo Onlus, Associazione Traumi Cranici Toscani ATRACTO Onlus, Associazione Vitadidonna Onlus, Associazione Vittorio Lodini progetto Seno, AVULSS Associazione di Volontariato nelle Unità Locali dei Servizi Sociosanitari, Palermo, Cerignola per l'oncologia Onlus, CFS Associazione Italiana Onlus, Cibo Amico allergia alimentare e anafilassi, CIDP Italia Onlus, CLEO Club Epatologi Ospedalieri, Diabete Brescia Onlus Brescia e Provincia, Diabete Zero Onlus, Difendiamoci dal Diabete Cittanova, Donna Per Donna Onlus, ESA Educazione alla Salute Attiva, Europa Donna Italia, Fand Ogliastra, Fand Milano, FAVO, Federasma e allergie, Federazione Alzheimer Italia, Federazione Diabete Sicilia, Federazione Italiana Incontinenti e Disfunzioni del Pavimento Pelvico Fincopp, Federazione Regionale Associazioni Toscane Diabetici Onlus, Fondazione Alessandra Bisceglia W Ale Onlus, Fondazione ANT Italia Onlus, Fondazione Attilia Pofferi Onlus, GILS Gruppo Italiano per la Lotta alla Sclerodermia Onlus, Gruppo di discussione e azione "Italia Glioblastoma Multiforme cancro al cervello", GSD Non Vedenti Milano Onlus, INSU' Associazione Giovani Diabetici Onlus, Inversa Onlus, InVIta la vita Onlus, La Lampada di Aladino Onlus, Le Donne Scelgono, Lega Italiana per la Lotta contro i Tumori Imperia Sanremo, Legaconsumatori Lucca, LIFC Piemonte Onlus, LILT Lega Italiana Per La Lotta Contro I Tumori, LILT Lega Italiana Per La Lotta Contro I Tumori Forli’ Cesena, LILT Lega Italiana Per La Lotta Contro I Tumori Ragusa, LILT Lega Italiana Per La Lotta Contro I Tumori Rimini, MEDeA Onlus, Pavia nel Cuore Onlus, Per Andare Oltre Onlus, Plus Onlus, PRODES Progetto Diabete e Salute Fand Roma, Progetto Luna, Progetto Luna Onlus, Progetto Vita Onlus, Salute Donna Onlus, SAMOT Onlus, Sardegna Medicina, Speranza Onlus Associazione Familiari Diversabili Psichici, Tarlov Italia Onlus, UFHa unione famiglie handicappati, Unione Italiana Lotta alla Distrofia Muscolare Pisa, Verso Il Sereno Onlus, Vivere senza stomaco si può, Voglia di Vivere Onlus, and WALCE Onlus.

We thank Dr Alessandra Lugo for assistance in data analysis and Gianna Costa for secretarial support. We are grateful to JD Baggott for editing the manuscript.

This study was funded by an unconditional grant received by the Mario Negri Institute IRCCS from the Permanent Observatory on Digital Innovation in Healthcare at the Politecnico di Milano.

\section{Conflicts of Interest}

None declared.

\section{Authors' Contributions}

PM and ES conceived the study. PM, SR, and ES participated in the design of the survey and the questionnaire and collected, managed, and analyzed data. All the authors contributed with data interpretation. PM, SR, and ES drafted the manuscript; PM, SR, EL, and ES critically reviewed the manuscript and approved the final version.

\section{Multimedia Appendix 1}

Questionnaire provided to participants (English version).

[PDF File (Adobe PDF File), 400KB-Multimedia Appendix 1]

\section{References}

1. Jacques Rose K, Petrut C, L'Heveder R, de Sabata S. IDF Europe position on mobile applications in diabetes. Diabetes Res Clin Pract 2017 Sep 07. [doi: 10.1016/j.diabres.2017.08.020] [Medline: 28951337]

2. Martínez-Pérez B, de la Torre-Díez I, López-Coronado M, Herreros-González J. Mobile apps in cardiology: review. JMIR Mhealth Uhealth 2013 Jul 24;1(2):e15 [FREE Full text] [doi: 10.2196/mhealth.2737] [Medline: 25098320] 
3. Pinto S, Caldeira S, Martins JC. e-Health in palliative care: review of literature, Google Play and App Store. Int J Palliat Nurs 2017 Aug 02;23(8):394-401. [doi: 10.12968/ijpn.2017.23.8.394] [Medline: 28854054]

4. Santoro E, Castelnuovo G, Zoppis I, Mauri G, Sicurello F. Social media and mobile applications in chronic disease prevention and management. Front Psychol 2015;6:567 [FREE Full text] [doi: 10.3389/fpsyg.2015.00567] [Medline: 25999884]

5. Piwek L, Ellis DA, Andrews S, Joinson A. The Rise of Consumer Health Wearables: Promises and Barriers. PLoS Med 2016 Feb;13(2):e1001953 [FREE Full text] [doi: 10.1371/journal.pmed.1001953] [Medline: 26836780]

6. Kantar Worldpanel ComTech. Marketwired. 2016. Kantar Launches Quarterly Report for Wearable Technology URL: http://www.marketwired.com/press-release/kantar-launches-quarterly-report-for-wearable-technology-2121234.htm [accessed 2018-11-14] [WebCite Cache ID 73wHYcjno]

7. Research2Guidance. 2017 Nov. mHealth App Economics 2017: Current Status and Future Trends in Mobile Health URL: https://research2guidance.com/product/mhealth-economics-2017-current-status-and-future-trends-in-mobile-health/ [accessed 2018-11-18]

8. Privacy Rights Clearinghouse. Jul 01. Mobile health and fitness apps: what are the privacy risks? URL: https://www. privacyrights.org/consumer-guides/mobile-health-and-fitness-apps-what-are-privacy-risks [accessed 2018-11-15] [WebCite Cache ID 73wOmzuYl]

9. BinDhim NF, Trevena L. Health-related smartphone apps: regulations, safety, privacy and quality. BMJ Innov 2015 Mar 05;1(2):43-45. [doi: 10.1136/bmjinnov-2014-000019]

10. Torous J, Roberts LW. The Ethical Use of Mobile Health Technology in Clinical Psychiatry. J Nerv Ment Dis 2017 Jan;205(1):4-8. [doi: 10.1097/NMD.0000000000000596] [Medline: 28005647]

11. Sunyaev A, Dehling T, Taylor PL, Mandl KD. Availability and quality of mobile health app privacy policies. J Am Med Inform Assoc 2015 Apr;22(e1):e28-e33. [doi: 10.1136/amiajnl-2013-002605] [Medline: 25147247]

12. Leenes R, van Barkel R, Gutwirth S, De Hert P. Data Protection and Privacy: (In)visibilities and Infrastructures. Cham, Switzerland: Springer International Publishing; 2017:796.

13. Volp KG, Mohta NS. NEJM Catalyst. 2017 Jul 10. Patient Engagement Survey: Technology Tools Gain Support — But Cost Is a Hurdle URL: https://catalyst.nejm.org/patient-engagement-technology-tools-gain-support/

14. European Commission. 2014 Apr 10. Green Paper on mobile health ("mHealth") URL: https://ec.europa.eu/ digital-single-market/en/news/green-paper-mobile-health-mhealth [accessed 2018-11-15] [WebCite Cache ID 73wbTUeQt]

15. Wu Y, Yao X, Vespasiani G, Nicolucci A, Dong Y, Kwong J, et al. Mobile App-Based Interventions to Support Diabetes Self-Management: A Systematic Review of Randomized Controlled Trials to Identify Functions Associated with Glycemic Efficacy. JMIR Mhealth Uhealth 2017 Mar 14;5(3):e35 [FREE Full text] [doi: 10.2196/mhealth.6522] [Medline: 28292740]

16. European Commission. 2014 Oct. Public Perceptions of Science, Research and Innovation URL: http://ec.europa.eu/ commfrontoffice/publicopinion/archives/ebs/ebs 419 en.pdf

17. Accenture Consulting. Patients Want a Heavy Dose of Digital URL: https://www.accenture.com/ acnmedia/PDF-8/ Accenture-Patients-Want-A-Heavy-Dose-of-Digital-Infographic-v2.pdf [accessed 2018-11-15] [WebCite Cache ID 73we9Azyx]

18. Carroll JK, Moorhead A, Bond R, LeBlanc WG, Petrella RJ, Fiscella K. Who Uses Mobile Phone Health Apps and Does Use Matter? A Secondary Data Analytics Approach. J Med Internet Res 2017 Dec 19;19(4):e125 [FREE Full text] [doi: 10.2196/jmir.5604] [Medline: 28428170]

19. Wen D, Zhang X, Lei J. Consumers' perceived attitudes to wearable devices in health monitoring in China: A survey study. Comput Methods Programs Biomed 2017 Mar;140:131-137. [doi: 10.1016/j.cmpb.2016.12.009] [Medline: 28254069]

20. Richards T, Montori VM, Godlee F, Lapsley P, Paul D. Let the patient revolution begin. BMJ 2013 May 14;346(may14 1):f2614-f2614. [doi: 10.1136/bmj.f2614] [Medline: 23674136]

21. SurveyMonkey. URL: https://www.surveymonkey.com/ [accessed 2018-11-18]

22. de Vries ST, Denig P, Lasheras Ruiz C, Houÿez F, Wong L, Sutcliffe A, IMI Web-RADR Work Package 3b Consortium. Interest in a Mobile App for Two-Way Risk Communication: A Survey Study Among European Healthcare Professionals and Patients. Drug Saf 2018 Dec;41(7):697-712 [FREE Full text] [doi: 10.1007/s40264-018-0648-0] [Medline: 29500800]

23. Eysenbach G. Improving the quality of Web surveys: the Checklist for Reporting Results of Internet E-Surveys (CHERRIES). J Med Internet Res 2004 Dec 29;6(3):e34 [FREE Full text] [doi: 10.2196/jmir.6.3.e34] [Medline: 15471760]

24. Bennett C, Khangura S, Brehaut JC, Graham ID, Moher D, Potter BK, et al. Reporting guidelines for survey research: an analysis of published guidance and reporting practices. PLoS Med 2010 Aug;8(8):e1001069 [FREE Full text] [doi: 10.1371/journal.pmed.1001069] [Medline: 21829330]

25. Covolo L, Ceretti E, Moneda M, Castaldi S, Gelatti U. Does evidence support the use of mobile phone apps as a driver for promoting healthy lifestyles from a public health perspective? A systematic review of Randomized Control Trials. Patient Educ Couns 2017 Dec;100(12):2231-2243. [doi: 10.1016/j.pec.2017.07.032] [Medline: 28855063]

26. Fox G, Garland S, Keibel A, Saxon LA. NEJM Catalyst. 2017 Sep 14. Why People Stick With or Abandon Wearable Devices URL: https://catalyst.nejm.org/stay-abandon-wearable-devices/ [accessed 2018-11-15] [WebCite Cache ID $\underline{73 w c g y o Y b}]$ 
27. Machado G, Pinheiro MB, Lee H, Ahmed OH, Hendrick P, Williams C, et al. Smartphone apps for the self-management of low back pain: A systematic review. Best Pract Res Clin Rheumatol 2016 Dec;30(6):1098-1109 [FREE Full text] [doi: 10.1016/j.berh.2017.04.002] [Medline: 29103552]

28. Huckvale K, Prieto JT, Tilney M, Benghozi P, Car J. Unaddressed privacy risks in accredited health and wellness apps: a cross-sectional systematic assessment. BMC Med 2015 Sep 07;13:214 [FREE Full text] [doi: 10.1186/s12916-015-0444-y] [Medline: 26404673]

29. Fan W, Yan Z. Factors affecting response rates of the web survey: A systematic review. Computers in Human Behavior 2010 Mar;26(2):132-139. [doi: 10.1016/j.chb.2009.10.015]

\author{
Abbreviations \\ CHERRIES: Checklist for Reporting Results of Internet E-Surveys \\ eHealth: electronic health \\ mHealth: mobile health
}

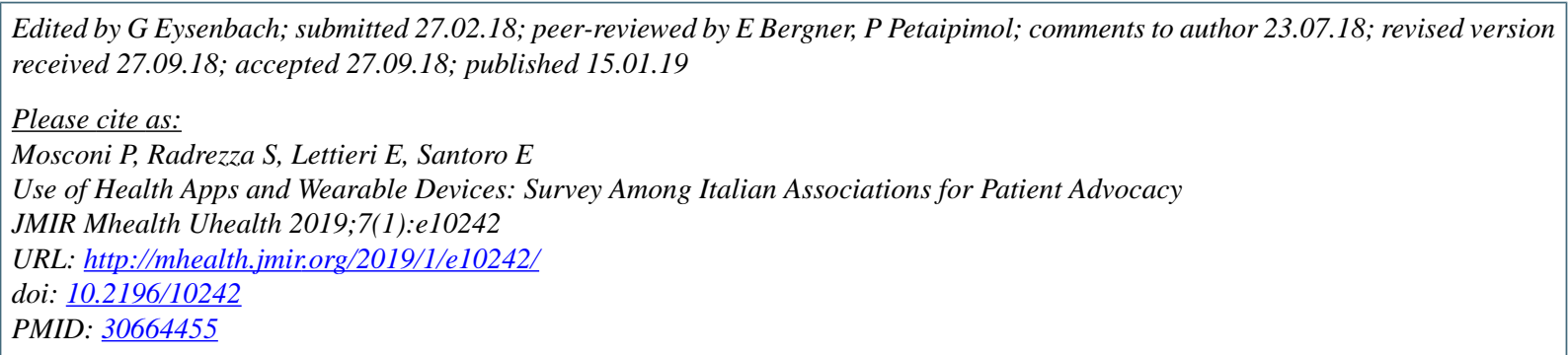

CPaola Mosconi, Silvia Radrezza, Emanuele Lettieri, Eugenio Santoro. Originally published in JMIR Mhealth and Uhealth (http://mhealth.jmir.org), 15.01.2019. This is an open-access article distributed under the terms of the Creative Commons Attribution License (https://creativecommons.org/licenses/by/4.0/), which permits unrestricted use, distribution, and reproduction in any medium, provided the original work, first published in JMIR mhealth and uhealth, is properly cited. The complete bibliographic information, a link to the original publication on http://mhealth.jmir.org/, as well as this copyright and license information must be included. 